\title{
The role of the media in influencing public attitudes to penicillin during World War II
}

\author{
Gilbert Shama (*) \\ (*) orcid.org/0000-0002-3566-0354. Department of Chemical Engineering, Loughborough University. \\ G.Shama@Lboro.ac.uk
}

Dynamis

[0211-9536] 2015; 35 (1): 131-152

Fecha de recepción: 10 de noviembre de 2013

http://dx.doi.org/10.4321/S0211-95362015000100006

Fecha de aceptación: 19 de noviembre de 2014

SUMMARY: 1.-Penicillin and the public consciousness. 2.-Alternative penicillin. 3.-Publicity control and conclusions

ABSTRACT: Penicillin's trajectory towards becoming an effective antibacterial chemotherapeutic agent took place during World War II. Its strategic military value was immediately recognised by the Allies, and mass production was undertaken with the prime objective of meeting the needs of the armed forces. News of its development came to be widely reported on in the media and is examined here. These reports frequently combined accounts of penicillin's prodigious clinical effectiveness with the fact that it was to remain unavailable to the civilian population essentially until the war had ended. More penicillin was to be made available to the civilian population in the United States than in Britain, but the sense that it was severely rationed remained as high. It was in response to this that the idea of «homemade penicillin» was hatched. News of this was also widely promulgated by both the British and American media. Although the numbers treated with penicillin produced in this way was never to be significant, knowledge of the existence of such endeavours may have served to assuage in some measure the feelings of frustration felt by the civilian population at penicillin's non-availability.

KEY WORDS: penicillin, World War II, radio broadcasts, press reports, homemade penicillin, vivicillin.

PALABRAS CLAVE: penicilina, II Guerra Mundial, radio, prensa, penicilina casera, vivicilina.

\section{Penicillin and the public consciousness}

In October 1942, following a BBC radio transmission on penicillin Howard Florey wrote a letter of complaint to the Corporation. He raised a number of objections about the accuracy of events portrayed in the broadcast, and then he asked if the $\mathrm{BBC}$ had considered whether it was in the public interest to «call attention to a substance of therapeutic value which is 
unprocurable except in minute amounts». The publicity that media reports on penicillin had brought him, he informed the BBC, had resulted in his receiving a «flood of pathetic letters from as far away as Western Australia and Saskatchewan» 1 .

Media reports on penicillin had started appearing soon after the publication of Florey's landmark articles in The Lancet in 1940 and 1941 which unequivocally demonstrated penicillin's clinical potential ${ }^{2}$. A brief item in The Scotsman in November 1940 reported a «hint» by Alexander Fleming that «Britain may have a drug even more effective than the sulphonamides ${ }^{3}$. Later, a piece in The Listener contained the enigmatic quotation from a contemporary issue of the British Medical Journal which stated that «penicillin is to other antiseptics what radium is to other metals» 4 . However, it was the summer of 1942 which marked the entry proper of penicillin into the public consciousness ${ }^{5}$. An article on the antibiotic had appeared in The Times in the summer of 1942 and this had sparked off the celebrated «palmam qui meruit ferat» exchange of letters between Sir Almroth Wright of St. Mary's Hospital in Paddington and Robert Robinson of Oxford University each determined that credit for penicillin should go to the right man -Alexander Fleming and Howard Florey respectively ${ }^{6}$. However, there were almost certainly other figures behind even these first exchanges that would develop into a - sometimes acrimonious-campaign of rivalry between St. Mary's and Oxford. It seems that the press had been tipped off in advance and that reporters had turned up at St. Mary's to interview Fleming on the morning on which Wright's letter was to appear. In particular, the hand of Charles M. Wilson, Dean of the Medical School at St. Mary's, has been implicated in this publicity coup ${ }^{7}$. Wilson was later enobled as Lord Moran and had the ear of senior establishment figures - he was Winston Churchill's personal physician, and a friend of Lord

1. Letter to the Director General of the BBC, 29 Oct 1942. Florey Archives, 98HF 247.1.2, Royal Society, London.

2. Chain, Ernst et al. Penicillin as a chemotherapeutic agent. The Lancet. 1940; 239: 226-228. Abraham, Edward P. et al. Further observations on penicillin. The Lancet. 1941; 238: 177-189.

3. Hope of a new drug. The Scotsman. 23 Nov 1940; 9.

4. A vital discovery. The Listener. 9 Oct 1941; 505.

5. Penicillium. The Times. 27 Aug 1942; 5.

6. Almroth Wright Letter to The Times. 31 Aug 1942; 5. Robert Robinson Letter to The Times. 2 Sep 1942; 5.

7. MacFarlane, Gwyn. Alexander Fleming. The man and the myth. Oxford: Oxford University Press; 1985, p. 256. 
Beaverbrook's whom he had previously successfully petitioned for funds when St. Mary's medical school was being built in the late $1920 \mathrm{~s}^{8}$.

Thereafter reporting on penicillin grew rapidly. Some indication of this can be gauged by counting the number of occurrences of the term «penicillin» in a major national newspaper -The Times. In 1942 there were just 7 articles containing the term and in 1943, 14 but by 1944 the number had risen to 93 before dropping slightly to 84 in $1945^{9}$. Early media accounts related the now well-known story of Fleming's accidental discovery, and then attempted to convey some idea of penicillin's prodigious activity against pathogenic bacteria. The most appropriate standard for this purpose was the sulphonamide class of drugs. Since the mid-1930s these synthetic agents had been the first truly effective line of defence against bacterial pathogens. Mention of these drugs in the context of penicillin had something to do with the fact that they had previously attracted media attention during their phase of development. In fact Lesch refers to them as having heralded «the era of miracle drugs» ${ }^{10}$. Although media interest in the sulphonamides was never as intense as it was to become for penicillin, in 1936 Time magazine named them «the medical discovery of the decade». Therefore, in one sense it can be said that the sulphonamides set the scene for what was to follow with penicillin. Perhaps the most well-known member of the class was sulphapyridine - known by its trade name, «M \& B 693», or more simply as just «M \& B». Penicillin was described as being «many hundreds of times» ${ }^{11}$ more active than the sulphonamides and, crucially, able to suppress the growth of sulphonamide-resistant bacteria. Some reports sought to put across penicillin's activity in more precise terms by citing the high dilutions - for example, 1 in 160 million - at which penicillin retained its activity ${ }^{12}$. It was evidently anticipated that such information might not be readily intelligible to the public and that some additional clarification

8. The existence of these behind the scenes interventions was suspected at the time; in a letter dated 19th June, 1944 to Edward Mellanby, Secretary of the Medical Research council (MRC) Florey complained of «a deliberate and clever campaign» to credit Fleming with all the research done on penicillin. He went on to lay the responsibility for the propaganda «at Lord Moran's door». Florey Archives, 98 HF 36.4.107, Royal Society, London.

9. The figures quoted were obtained by entering «penicillin» as the search term in the digital Times archive: http://find.galegroup.com

10. Lesch, John E. The first miracle drugs. How the sulfa drugs transformed medicine. New York: Oxford University Press; 2007.

11. The Times, n. 5.

12. The Times, n. 5. 
might be needed: «Let me try and give you a picture of what this means», the broadcaster of Ariel in Wartime transmitted in the autumn of 1942 cosily proposed:

«Now supposing we were able to have a very large container of about 300 gallons of culture medium, and we added staphylococci in suitable amount, followed by only about 1 grain of the purest penicillin and then kept the container at blood heat for 24 hours, this minute amount of penicillin would prevent the multiplication of germs and the liquid would remain quite clear» ${ }^{13}$.

Appearing at the same time were explicit statements as to what official policy on the distribution of penicillin was to be. The title of an article in The Times published in the summer of 1943; «No penicillin for the public: fighting services first» ${ }^{14}$ succinctly conveyed what this was to be. The situation in Britain was that the pharmaceutical industry had shown little enthusiasm for producing penicillin in the early stages of the war and Florey had turned his attention to its counterpart in the United States which proved far more receptive. British firms did eventually start producing penicillin, but production was primarily based on the far less efficient method of «surface culture». The innovations brought about in the United States of «submerged fermentation», isolation of improved strains of $P$. notatum and the optimisation of the composition of the growth medium described in detail by Hobby ${ }^{15}$ were only slowly adopted in Britain with the result that penicillin output was to remain far below requirements for all but the final stages of the war.

Sections of the press were quick to seize upon instances of human tragedy resulting from the implementation of this policy. A desperately sick child stricken with an infection curable only with penicillin but who was ultimately denied it with fatal consequences provided exactly the right ingredients ${ }^{16}$. The message was not solely confined to adult readerships; stories about the curative effects of penicillin and its rarity were featured in American comic books aimed at children ${ }^{17}$. Florey overcame his reticence

13. Arial in wartime. BBC Radio Broadcast, 4 September 1942.

14. No penicillin for the public. The Times. 28 Aug 1942: 2.

15. Hobby, Gladys L. Penicillin: Meeting the challenge. New Haven: Yale University Press; 1985.

16. The Daily Mirror. 2 Feb 1942: 1.

17. Hansen, Bert. Medical history for the masses: how American comic books celebrated heroes of medicine in the 1940s. Bulletin of the History of Medicine. 2004; 78: 148-191. 
towards the media and made a radio broadcast on penicillin in December 1943 in which he said that it was «very right and proper» that penicillin should be reserved for the armed forces given its value in treating war wounds ${ }^{18}$. There would have been many with relatives in the armed forces who would have been re-assured by the news that the life-threatening infections that frequently took hold following battle injuries could be effectively countered once the national supply of penicillin had been built up sufficiently to permit comprehensive treatment of wounded servicemen. The impact on civilian morale of such intelligence was also exploited in the United States ${ }^{19}$ where, in contrast to Great Britain as discussed further below, provision for allocating a proportion of the penicillin being produced for meeting the needs of civilians had always constituted an important consideration. There would also have been among newspaper readerships and radio audiences individuals who were either suffering from intractable infections that were resistant to the sulphonamides, or who were caring for those who were. The former were in the words of The Times «beyond the reach of treatment» ${ }^{20}$. Media accounts of the existence of an apparently miraculous new drug under development - but apparently out of reach- would have engendered feelings of despair and frustration amongst sufferers and their carers, and would have induced some of them to approach scientists who had been identified in the media as working on penicillin in attempts to obtain it -the «flood of pathetic letters» that Florey had complained of.

The issue of the provision of penicillin to the civilian population of Britain was only to receive formal attention much later in the war. In May 1944 prominent British penicillin research workers met with officials at the Ministry of Health to «consider the principles upon which supplies of penicillin should be distributed when it becomes available, and to consider the machinery of distribution ${ }^{21}$. The Chairman, Sir Weldon DalrympleChampneys, reminded those present that supplies of penicillin were available only for the use of the armed forces and to a limited extent for clinical investigations. However, as a result of publicity regarding production

\footnotetext{
18. Penicillin. BBC Radio Broadcast, 20 Dec 1942.

19. An article in a women's magazine (Gardner, Mona. Miracle from mold. Womans Home Companion. Sep 1943: 70-72) contained the following: «Everybody with a husband, son or sweetheart in the armed forces will thrill to the story of penicillin - a new germ - killer acclaimed as more potent than the fabulous sulfa drugs».

20. The Times, n. 5.

21. National Archives, London. Penicillin: supplies policy, MH 58/360.
} 
figures in the United States and the treatment of «prominent persons», it might become necessary on "political grounds» to make a certain quantity available for the civilian population. One of the members of the committee, Professor R. V. Christie, stated that he had come to the conclusion that it was not feasible to «pick and choose between deserving cases». He pointed out that the USA had a «large organisation, equipped with aeroplanes», to investigate civilian cases for which penicillin was called for. $\mathrm{He}$ and Alexander Fleming had undertaken to arrive at an estimate of civilian requirements based on figures obtained from the Registrar-General's return of deaths from conditions for which penicillin would be suitable. They arrived at a figure of 6,000 mega units per annum, and further estimated that if penicillin distribution were to be made unrestricted, the figure would be closer to 10,000 mega units. Based on this he recommended that there should be no general penicillin distribution until production permitted this. He added that if to meet «political pressure» supplies were released at a lower rate, there would be «an even greater outcry against misuse». It was further pointed out that production in Britain was perhaps one-thirtieth of American production and was only $10 \%$ of what had been requested for the treatment of battle casualties and that therefore the question of distribution to civilians was not a «live one at the present time».

In the United States the transition from small scale to industrial scale manufacture of penicillin was to come under the auspices of the War Production Board (WPB). From1944 the WPB became the centre of a large network sharing information and expertise across twenty five companies. Under these arrangements the participating companies received hefty amounts of government support for the plants they built during the war and which were purchased back at half price once the war had ended ${ }^{22}$. It was inevitable that the companies involved should seek to take advantage of these arrangements. One company, Commercial Solvents, came under criticism for over-elaborate specification of buildings to be used for housing penicillin producing facilities. An inspector wondered «whether [Commercial Solvents] have heard that a war is being fought» ${ }^{23}$. The participating companies came to view the publicity in the media as free advertising for themselves and something which they would ultimately benefit from after

\footnotetext{
22. Bud, Robert. Triumph and tragedy. Oxford: Oxford University Press; 2007, p. 45-46

23. Neushul. J. Science, government and the mass production of penicillin. The Journal of the History of Medicine and Allied Sciences. 1993; 48: 371-395.
} 
the cessation of hostilities ${ }^{24}$. Moreover, the scale of plant under construction was obviously ultimately determined by estimates of demand for penicillin and under such arrangements the tendency would have been to inflate these. Helfand et al. identify the profit motive as one of the driving forces for the enthusiastic involvement of the American pharmaceutical industry, but point out that this existed side by side with what they refer to as the «humanitarian instincts» of the industry ${ }^{25}$.

The British approach for the duration of the war was to remain one of striving to ensure that penicillin production should be such as to meet all military needs, whereas in the United States, the objective was to not only satisfy military requirements but to seek to meet civilian needs in such cases where the use of alternative therapies had proved inadequate ${ }^{26}$. A very important factor in this was that in March 1944 the first commercial plant operated by Pfizer for large scale production of penicillin by the more efficient submerged fermentation had come on stream. This was replicated by other pharmaceutical companies with the result that in the second half of 1944 penicillin production in the United States soared ${ }^{27}$.

In fact considerations in the United States very similar to those held at the Ministry of Health in Britain were actually put in place fully one year before. Adams describes how as early as 1940 plans were put in place to ensure «medical preparedness» in the event of the country being drawn into the war ${ }^{28}$. A committee on chemotherapeutics and other agents (COC) was established to evaluate drugs for the treatment of infections in battle casualties. The committee first concentrated on the sulphonamides, but from 1943 onwards focussed its attention on penicillin. An allocation of penicillin was made available for treating civilians and strict guidelines were established and adhered to by the committee's chairman, Chester S. Keefer, for its dispensing for civilian cases. Keefer's role in the process of allocating what were severely limited quantities of penicillin to civilian patients came

24. Adams, David P. The Penicillin mystique and the popular press (1935-50). Pharmacy in History. 1984; 26: 134-142.

25. Helfand, W. H; Woodruff, H. B; Coleman, K. M. H; Cowen, D.L. Wartime industrial development of penicillin in the United States. In: Parascandola, John, ed. The history of antibiotics: a symposium. Madison. American Institute of the History of Pharmacy; 1980, p. 31-56.

26. Liebenau, J. The British success with penicillin. Social Studies of Science. 1987; 17: 69-86.

27. Hobby, n. 15, p. 185-6.

28. Adams, David P. «The greatest good to the greatest number». Penicillin rationing on the American home front, 1940-1945. New York: Peter Lang; 1991. 
under keen press scrutiny. Under the headline «Heartbreaking King Solomon Dilemmas of Judge Keefer», a newspaper article asked its readers whether they would be willing to «swap jobs with the allocator of life-saving drugs who decides whether a soldier, sailor, civilian, child or adult must face death so that others can live?» ${ }^{29}$. One of the cases featured in this news item was that of a young girl, Patsy Malone, whose life was saved by the supply of penicillin to the physicians treating her.

Adams has shown how in media reports in the popular press of the period information on any negative side-effects following administration of penicillin was suppressed in order to present it as an ideal drug ${ }^{30}$. This is in contrast to the sulpha drugs where Time magazine informed its readers that «toxic reactions... are trequent» ${ }^{31}$. But even the suppression of information about penicillin's side effects is to understate penicillin's standing in the collective consciousness of the medical profession as well as that of the general public. In a recent article, Santesmases and Gradmann made mention of how the very perception of disease and therapy was changed by drugs such as penicillin, and how medical successes with the first antibiotics led to the creation of the notion -later proved to be hopelessly optimistic- that infectious diseases could be eliminated altogether ${ }^{32}$. This was the atmosphere in which the curative powers of penicillin extended beyond infectious diseases. One newspaper informed its readers that «Penicillin restores the mind ${ }^{33}$. The report claimed that seven patients at Rubery Mental Hospital in the West Midlands of England were treated with penicillin and five were cured. Free reign was given to the individual behind the scheme, Dr. T. C. Graves, to expound his belief that «all mental disorders are caused by germs». Graves was in fact one of the principal proponents of the so-called «focal sepsis theory» which held that infection of hard tissue such as bone and teeth could result in mental disease. Needless to say, the press seized on this account with the result that the relatives of those with mental illness were added to the civilians clamouring for penicillin ${ }^{34}$. Controversial even

\footnotetext{
29. The American Weekly. 17 Oct 1943.

30. Adams, n. 24.

31. Sulfa Drugs: Debits and Credits. Time Magazine. 14 Jun 1943.

32. Santesmases, María Jesús; Gradmann, Christoph. Circulation of antibiotics: an introduction. Dynamis. 2011; 31: 293-303.

33. Penicillin restores the mind. The Daily Mail. 20 Jul 1945; 3.

34. National Archives, London. Penicillin: treatment in mental disorder. MH 58/631.
} 
at the time, this view fell into disfavour not long after the end of the war ${ }^{35}$. Further still, one researcher in the United States was prompted to investigate penicillin's action against a certain type of cancer cell. Positive results were obtained and were published in the prestigious journal Science ${ }^{36}$ and were duly reported on in the popular press ${ }^{37}$. This particular news item probably explains the presence in archives both in Britain and the United States of letters from cancer sufferers desperate to acquire penicillin.

\section{Alternative penicillin}

The complete chemical synthesis of penicillin, that is its production without recourse to a mould, was frequently cited as the breakthrough that would ultimately solve the problem of penicillin shortages ${ }^{38}$, but this was tempered by the news that this approach was fraught with difficulties, as indeed it was; the chemical structure of penicillin was to prove particularly difficult to elucidate. The structural formula was only obtained in 1945 and chemical synthesis only demonstrated in $1956^{39}$.

Penicillin production was therefore to remain irrevocably bound to the metabolism of moulds. In his original article Fleming had shown that the ability to produce penicillin was rare amongst strains of the species he had isolated ${ }^{40}$. However, when it came to describing the mould that produced

35. Scull, Andrew. The insanity of place/the place of insanity: essays on the history of psychiatry. London: Routledge; 2006.

36. Cornman, Ivor. Survival of normal cells in penicillin solutions lethal to malignant cells. Science. 1944; 99: 247.

37. Medicine: answer to cancer? Time Magazine. 3 Apr 1944. The idea that fungal metabolites may possess anti-tumour activity is not so far-fetched; see for example, Jong, S. C.; Donovick, R. Antitumor and antiviral substances from fungi. Advances in Applied Microbiology. 1989; 34: 183-262. The species Penicillium citrium is the source of the highly effective statin, mevastatin, and this has led to it being referred to as the «penicillin of the heart». Lie, Jie Jack. Triumph of the heart: the story of the statins. Oxford: Oxford University Press; 2009.

38. The Scotsman, n. 3.

39. Sheehan, John C. The enchanted ring; the untold story of penicillin. Cambridge, Mass.: MIT Press; 1982. Sheehan C.; Henery-Logan, K. R. The total synthesis of penicillin. Journal of the American Chemical Society. 1957; 79: 1262-1263. Chemical synthesis was never to become an economically viable way of producing penicillin and has only ever been produced via the fungal route.

40. Fleming, Alexander. On the antibacterial action of cultures of a penicillium, with special reference to their use in the isolation of B. influenza. British Journal of Experimental Pathology. 1929; 10: $226-236$. 
penicillin to the essentially lay readership of newspapers this fact tended to get submerged. In attempting to describe Fleming's mould recourse was instead frequently made to the familiar. According to The Listener Fleming's mould was «very much like the moulds you find on last week's bread or the week's before sausages». The New York Times stated that penicillin was «a new chemical substance elaborated by a special strain of mold in bread and Rocquefort cheese». Time magazine described $P$. notatum as «a relative of the cheese mold». Indeed in one instance even the circumstances leading to that momentous event in St Mary's Hospital, Paddington were likened to the «housewife making jam [who] may find that into one jar a spore of mildew has settled and begun to grow forming a white furry mass on the surface of the jam, so on to one of Professor Fleming's plates of jelly a mould settled» ${ }^{41}$.

One consequence of attempts by the media to make the apparently miraculous familiar may have been to prompt some individuals to attempt to produce their own penicillin. The practice of using moulds for their curative properties has ancient origins and seems to have persisted through to modern times; Wainwright ${ }^{42}$ relates how in the late 1920 s the mother of a young British girl suffering from impetigo was instructed by her GP to prepare a starch paste, allow it to spontaneously go mouldy and then to make a poultice for application to the affected parts. This procedure apparently resulted in a complete cure. An individual of Hellenic origin wrote to The New York Times explicitly pointing out the connection between the practice in rural areas of Greece of applying mouldy bread to superficial infections and the contemporary interest in penicillin ${ }^{43}$. If indeed the publicity about penicillin and its fungal origins led to a revival in the use of moulds for treating infections by individuals, it is most unlikely that such practices would have been documented. Notwithstanding, isolated accounts did appear in the press ${ }^{44}$. What might possibly have been interpreted as encouragement for home-based production coupled with a supposed example of official disdain for the civilian clamour for penicillin is illustrated in an article in

41. Fletcher Charles M. Health from mould. The Listener. 23 Sep 1943, 354 (Also broadcast by the BBC Indian Service). The Listener. 9 Oct 1941. The New York Times. 6 May 1941. Time. 15 Sep, 1941.

42. Wainwright, Milton. Moulds in ancient and more recent medicine. Mycologist. 1989; 3: 21-23.

43. The New York Times. 11 Nov 1943.

44. He Grows Penicillin on a Potato. The Daily Mirror. 23 Jul 1945: 5. 
an American newspaper ${ }^{45}$. Readers were casually informed that the mould was «so easy to grow that it is discarded as worthless during commercial production of chemically refined penicillin». The report was in fact accurate on two counts: the mould had indeed become «easy to grow» as a result of research directed towards optimising the composition of the growth medium. Another contributory factor was advances in the techniques used to culture the mould. Taken together these resulted in increased yields of both fungal biomass and penicillin. Moreover, the fungal biomass was indeed disposed of at the end of the fermentation process. Despite this the report was ultimately misleading in seeking to link the two factors together. Re-use, or recycling, of mould biomass was never contemplated at an industrial scale of production. The greatest risk attendant upon such an operation would have been one of contamination by environmental micro-organisms. Even today with the availability of considerably more advanced technology this type of operation is unheard of in the pharmaceutical industry, and mould biomass continues to be simply discarded.

General Practitioners too would have become increasingly accustomed to coming across clinical accounts on penicillin in journals such as The Lancet, The British Medical Journal and the Journal of the American Medical Association and must also have experienced frustration at not being able to procure it for their patients. In the autumn of 1943 a method of producing gauze impregnated with crude penicillin for clinical applications was published in Science ${ }^{46}$. The method came to be championed by a certain Dr. Julius A. Vogel, a plant physician for a steel corporation. The Times Herald featured the method in an illustrated two page report in. The article, written by the paper's Science Editor, Wilson Scott, began with the words «I have just made penicillin, the magic drug». In the article Vogel was reported as having addressed a meeting of the Industrial Hygiene Association earlier in the same month in the following terms:

«Dare any man say that penicillin is scarce? Certainly money can't buy it, but each and everyone here present can easily produce his own penicillin

\footnotetext{
45. The Times Herald. 28 Nov 1943.

46. Robinson, George H.; Wallace, Jas E. An inoculated penicillin dressing. Science. 1943; 98: 329330.
} 
in his own family kitchen at an initial outlay of less than $\$ 5$ dollars, and at a production cost of less than 5 cents per Petrie (sic) dishful» ${ }^{47}$.

The Times Herald reported that Vogel had treated some 29 patients most of whom had responded well to treatment. It then went on to depict Vogel's procedure in a step-by-step guide that occupied two entire pages. Scott demonstrated how a piece of gauze should be cut to size and placed in the bottom of a petri dish, whereupon it was moistened with some starch-based growth medium before being inoculated with spores of Penicillium. The petri dish was incubated for 4 days after which the gauze could be applied directly as a poultice onto «external cuts, wounds and abrasions». Scott happened to be particularly well qualified to undertake these procedures as he had received training under Robert D. Coghill at Yale University. Coghill was at the time Chief of the Fermentation Division at the US Department of Agriculture's (USDA) laboratories at Peoria, Illinois where perhaps the single greatest process innovation - that of so-called submerged fermentation - was pioneered. In his position at USDA Coghill would have had access to the most productive strains of $P$. notatum, and it is almost certain that he obliged his former student with a suitable strain: ordinary members of the public would not have fared so well. The article did carry a brief warning that «home production» of penicillin i.e. by lay persons was "fraught with danger» but when considered alongside the overall tone of the article seems to have been inserted as a mere gesture: the item was nothing short of out and out encouragement for homemade penicillin production.

News of this method was to cross the Atlantic; applying the appropriate currency conversion factor, on $18^{\text {th }}$ November 1943 the News Chronicle carried a story entitled «Penicillin made for 3d. in kitchen». Later, an item in the News Review of 27th April, 1944 informed its readers that Penicillium notatum was «easily grown at room temperature on gauze moistened with a watery solution of minerals and sugar». With little thought of the consequences the article informed its readers that «an endless supply of ever-growing Penicillium mould is held by the Lister Institute's National Collection of Type Cultures' (NCTC) and was available to accredited investigators for growing mould at home» - a somewhat ambiguous statement. Amongst the records of the NCTC a letter has survived from a 
private individual seeking to obtain a culture of $P$. notatum. The applicant, a certain Mrs. Good, made direct reference to the article in News Review. She stated that where she lived she enjoyed a warm climate and often found mould growing on cheese and curds; would the Penicillium mould grow on cheese she wondered? She would never be allowed to find out; her request was refused by the curator, Dr. R. St. John-Brooks.

Concern of a more sincere tone came to be expressed in medical journals over the potential hazards of «Do It Yourself» penicillin production. In fact Coghill had co-authored a letter with the mycologist Kenneth Raper in an American Medical Journal on the difficulties of attempting to isolate penicillin-producing stains of penicillia and of the dangers of contamination of cultures by harmful organisms if untrained persons attempted to make their own penicillin ${ }^{48}$. There were indeed dangers in handling liquid culture media containing sugars and other nutrients under non-aseptic conditions. Were crude filtrates or gauzes impregnated with filtrate to become contaminated by micro-organisms present in the environment prior to being applied to superficial infections this would almost certainly lead to the exacerbation of the condition.

Despite the official warnings about dabbling in amateur penicillin manufacture, anyone using solid substrates such as bread or starch pastes was at considerably less risk than those using dilute sugar solutions which could become host to a wide variety of microbial contaminants including pathogenic ones. This is not to say that moulds isolated on such substrates would necessarily be producing penicillin. Moulds elaborate a wide variety of secondary metabolites a number of which exhibit inhibitory action towards bacteria. That a significant number of these turn out to be toxic if taken systemically in purified form came to be discovered in the years following the war and in particularly in the 1960s when antibiotic discovery was at its peak. Indeed one clandestine attempt to produce antibiotics in Occupied Holland centred on the mould Penicillium expansum -a common contaminant of apples- and some cures were reported ${ }^{49}$. It was only years later that it was discovered that the principal antibiotic produced by this species was possibly due to the antibiotic patulin, which is in fact

48. Raper, K. B.; Coghill, R. D. «Home made» penicillin. Journal of the American Medical Association. 1943; 123: 1135.

49. Combined Intelligence Objectives Sub-Committee. Dutch scientific institutions in Utrecht and Amsterdam. London: HM Stationary Office; 1945. 
carcinogenic when taken parenterally but may prove effective when applied to topical infections ${ }^{50}$. Similarly in the Soviet Union the antibiotic produced by Penicillium crustosum was used in the early stages of the war to treat battle casualties ${ }^{51}$.

The concept first proposed by Robinson and Wallace and mentioned above for producing penicillin-impregnated gauze was to receive further attention from research workers, and articles on the method continued to appear in medical journals both in Britain ${ }^{52}$ and in the United States ${ }^{53}$. The medical conditions treated using penicillin-impregnated gauze included carbuncles, scalds, syphilitic ulcers and osteomyelitis, and in the majority of cases positive outcomes ensued.

In Britain a pharmacist, Kenneth White, succeeded in producing small amounts of penicillin that he supplied to local general practitioners who used it to treat various types of superficial infections ${ }^{54}$. News of his activities was reported by both the local and national press ${ }^{55}$. White had premises in Ripley in Surrey and told the Daily Mirror that he produced his first batch of penicillin in April 1944. Just where he got his strain of $P$. notatum is uncertain, but as a pharmacist he would have had contacts in the pharmaceutical industry, and it is possible that one of these may have assisted him in acquiring a suitable strain. White cultured the mould in glass vessels of the type widely used in industry and had his filtrates assayed at a local hospital by a pathologist who used the «Oxford» Staphylococcus aureus strain. In association with a local physician White published brief case reports in the trade press of patients who had been treated with penicillin produced by him. It was claimed that of the 17 cases reported 15 showed definite improvements after treatment with the crude filtrate ${ }^{56}$.

50. See for example, Dickens, F.; Jones, H. E. H. Carcinogenic activity of a series of reactive lactones and related substances. British Journal of Cancer. 1961; 15: 85-100.

51. Yermolieva, Z.; Kaplun, T.; Levitov, M. Penicillin Crustosin. American Review of Soviet Medicine. 1945; 2: 247-250.

52. Alston, J. M. Use of crude Penicillium filtrate for local treatment. British Medical Journal. 1944; 1: 654-655. Hobson, A. J. and Galloway, L. D. Home-made penicillin. The Lancet. 1944; 243: 230-231.

53. Myers, R. S. et al. The use of gauze impregnated with Penicillium notatum or impregnated with crude penicillin in the treatment of surface infections. New England Journal of Medicine. 1944; 231: 761-764.

54. Surrey History Centre, Woking. The Ripley Pharmacy, Ripley: 8468.Papers relating to penicillin.

55. The Daily Mirror. 3 Jun 1944: 5. Brighton and Hove Gazette. 10 Jun 1944: 1.

56. Creet, R. A. F.; White, K. E. Penicillin filtrate in general practice. The Pharmaceutical Journal. 23 Sep 1944: 124. 
Forms of crude penicillin were also developed by an émigré German doctor, Hans Enoch, who had acquired extensive chemical processing experience through managing a company producing sera and vaccines in Hamburg. Because he was Jewish he was barred from supplying medicines when the Nazis took power, and he left for Britain in 1935. He established the International Serum Company in Norwich but soon after moved to London where he took on a partner, W.K.S. Wallersteiner. The company became successful largely due to its ability to offer a 24 hour serum delivery service $^{57}$. In 1940 Enoch came to be interned as an enemy alien but was subsequently released and allowed to return to his former activities. Whereas rabbits and guinea pigs are typically used for generating sera in the laboratory, the production of sera for clinical application is more efficiently conducted using larger animals such as goats or horses; Enoch favoured horses. However, wartime conditions made it difficult for him not only to obtain horses for this purpose, but also the means of maintaining them, as even fodder was in short supply. The business suffered as a result and he sought for other means to make a living. Enoch had received bacteriological training in Germany and the publicity over penicillin evidently attracted his attention. Given the unavailability of penicillin to the civilian population he decided to attempt to satisfy the demand for the antibiotic. He was to manufacture two products, the first was «vivicillin» and the second «pennotin». The latter was found to only be suitable for topical application and was produced by growing strains of Penicillium on tea leaves -a technique he had apparently been introduced to by one of his professors, Hugo Carl Plaut of Hamburg University ${ }^{58}$.

Together with Wallersteiner he published a letter in Nature ${ }^{59}$ claiming that they had obtained antibacterial effects from crude Penicillium filtrates that were actually greater than those of penicillin. The material used was, according to the article, «a suspension of Penicillium notatum (Fleming) hyphae in a fluid medium, obtained from below the mycelium of the mould». This was widely reported in the press ${ }^{60}$. Enoch was reported in one news story to be «working secretly in a Hendon laboratory» (in fact his home),

\footnotetext{
57. Enoch, M. H. British Medical Journal. 304; 1992:1374.

58. Imperial War Museum, London. H. Enoch. HE/1, p. 210.

59. Enoch, Hans; Wallersteiner, W. K. S, A standardized antibacterial pyrogen-free metabolite preparation containing living Penicillium notatum, Nature 1944; 153: 380-381.

60. Wellcome Archives, London. Vivicillin. WF/TRC/02/004.
} 
and that the name "vivicillin" which he had coined was derived from "vivus", living and penicillium, a mould». In yet further revelations Enoch was reported as apparently having injected himself with a «virulent culture», and then with vivicillin; in the words of the report «vivicillin triumphed». In actual fact Enoch had accidentally infected himself with swine erysipelas following a cut he had received to his right hand in a laboratory accident. The hand swelled up and became painful and therefore he decided to obtain treatment using vivicillin that he had produced. He did not treat himself but received treatment at Hammersmith Hospital and reported that the treatment was successful ${ }^{61}$.

News about vivicillin also came to be reported in the United States and Edward Mellanby at the MRC was informed of this by colleagues from the Rockefeller Foundation in June, $1944^{62}$. The news item on vivicillin sent to Mellanby was from Time magazine and bore the title «Penicillin Echoes». The article itself described vivicillin as a «cheap, simplified form of penicillin». Florey came to hear about vivicillin from a number of different sources but was to remain highly sceptical about the various claims made for it which is hardly surprising given his attitude to the press and his suspicion of those who sought publicity for themselves. In a letter to Mellanby dated $29^{\text {th }}$ April, 1944, he stated that he had been rung up by a reporter from the News Chronicle and he referred to vivicillin as «an absolute racket» and that «in the state of communications existing at present, this story you can be sure will be round the world» ${ }^{63}$. In another letter to Professor LP Garrod of St Bartholomew's Hospital in London dated 17th May Florey wrote that vivicillin was «a complete racket and Chain tells me that Enoch says that Wallerstein (sic) is dishonest, or something to that effect» ${ }^{64}$. Despite Florey's strong views on vivicillin it was reported at the 10th Meeting of the General Penicillin Committee held on 11th May, 1944 that «Dr. Burgin and Dr. Kennedy had visited Dr. H. Enoch and had formed the opinion that Vivicillin was worthy of investigation» ${ }^{65}$. Florey, a member of the Committee, was absent from that particular meeting. Another committee member, Professor Ronald V. Christie, Herts, had been present at the meeting but evidently

\footnotetext{
61. Imperial War Museum, n. 58, p. 210.

62. National Archives, London. Vivicillin as a proposed substitute for penicillin. FD 1/7004.

63. Florey Archives. Royal Society, London. 98 HF 36498.

64. Florey Archives. Royal Society, London. 98 HF 24763.

65. Florey Archives. Royal Society, London. 98 HF 35.10.166.
} 
differed from the Committee's recommendation regarding vivicillin, and he wrote to Florey with his reservations. In his response dated $25^{\text {th }}$ May 1944 Florey wrote «I entirely agree with you that nobody should be asked to spend their time at this juncture fiddling about with vivacillin» ${ }^{66}$. Later in the same year the results of clinical trials conducted with vivicillin were published in The Lancet ${ }^{67}$. The location of the trials was simply given as «a military hospital in England». Some dozen cases were reported on and the conclusion of the team that had conducted the tests was that vivicillin had no bacteriostatic or therapeutic effect on the cases treated.

In fact, Florey continued to receive correspondence on vivicillin well after the war had ended. A representative of the International Serum Company wrote to Florey in January of 1951 in an almost apologetic tone stating that vivicillin and pennotin had been developed during the war when there were shortages of penicillin, and that at no time did they state that their products were better than penicillin. Production was apparently continuing but this was purely for «veterinary purposes and exports» 68 .

\section{Publicity control and conclusions}

Even if the authorities in Britain and the United States had wanted to keep the penicillin programme secret, its sheer scale involving as did thousands of people working in academic and industrial laboratories and pharmaceutical manufacturing sites both in Britain and the United States, would have made this an impossible task. Indeed, there may even have been official sanctioning for the first news items to appear in The Times in the autumn of 1942 because of their favourable propaganda value at a time when there was overwhelmingly bad news for the Allies from the

\footnotetext{
66. Florey Archives. Royal Society, London. 98 HF 41.7.40.

67. Crawford, T., Handley, R. S., Hargreaves, W. H. Clinical trial of a Penicillium preparation. The Lancet. 1944; 1: 738-739.

68. Florey Archives. Royal Society, London. 98HF 2105 8. The possibility that Enoch's preparation may have had some antibacterial properties additional to that of penicillin is actually not that far-fetched. A microbiologist with impeccable credentials — Gladys Hobby — was involved in some investigations of such phenomena. Hobby, Gladys L.; Lenart, Tulita F. ; Hyman, Beverley. The effect of impurities on the chemotherapeutic action of crystalline penicillin. Journal of Bacteriology. 1947; 54: 305-323.
} 
war front; Singapore had fallen to the Japanese and the Red Army was in retreat ${ }^{69}$. As a counter to this here was a British discovery that possessed the ability to overcome many of the most feared bacterial agents of disease and infection. Moreover, plans for its mass production were being undertaken jointly in Britain and the United States, and this would have added to its propaganda value. This marks the time when, as Bud has put it, penicillin became «public property» ${ }^{70}$.

However, the relationship between the various government agencies with responsibility for penicillin and the subject of publicity over the antibiotic turned out to be more complex. For one thing, penicillin was never to entirely displace the sulpha drugs during the war years, and indeed the initial perception of penicillin was that it would supplement rather than displace them. In the United States peak production of sulpha drugs was achieved in 1943 with production dropping off in the following year as penicillin gained ascendency ${ }^{71}$. American servicemen were issued with packets of sulphadiazine and sulphanilamide for self-administration in the event of becoming wounded. Moreover, these compounds were even given prophylactically to American troops in battle zones in the belief that this would reduce incidences of wound infection until a study showed that use of their use, and indeed any antibacterials including penicillin, did not lead to improved outcomes for those wounded ${ }^{72}$. Adams makes the point that no official attempts were made to discourage publicity over the sulpha drugs in the United States because such publicity served to divert attention from penicillin ${ }^{73}$.

The evolving attitude to publicity for penicillin in Britain may be gauged from the minutes of the General Penicillin Committee ${ }^{74}$. The aim of the committee was primarily to co-ordinate commercial production and to consider all matters that impinged on this. This included the issue of censorship of all forms of publication involving penicillin. At its first meeting the emphasis seemed to be on preventing publication of any information

69. Brown, Kevin. Penicillin man. Alexander Fleming and the antibiotic revolution. Stroud: Sutton Publishing; 2004, p. 137.

70. Bud, n. 22, p. 38.

71. Lesch, n. 10, p. 220.

72. Lesch, n. 10, p. 243.

73. Adams, n. 28, p. 104

74. British Library, Alexander Fleming Papers Volume VIII, 56113, General Correspondence, 19241944. The committee was established following a conference in late September 1942. 
that could provide the enemy with the means of establishing their own penicillin production, and there was general agreement that all press and radio reports should be censored. By the fifth meeting in July 1943 it was agreed that there would be no objection to publications of a «general nature» about penicillin, but that any articles published should make clear that none was available for general use. At the meeting in October of the same year the tone had changed and the concern was expressed that the British contribution towards the mass production of penicillin was not receiving due acknowledgement. The suggestion was put forward that the Directorate of Medical Supplies should perhaps consider producing a special publication for the layman with a title such as «The Battle on the Drug Front» or «Bottles into Battle».

A quite different source reveals that the greatest sensitivity appears to have been reserved for so-called «chemical studies», i.e. investigations aimed at elucidating the chemical structure of penicillin and at establishing a route to its chemical synthesis ${ }^{75}$. The concern here was primarily one of German pre-eminence in synthetic organic chemistry. But even in this sphere of research there were lapses in security; at the meeting of the General Penicillin Committee in March 1943 it was noted and deplored by one of the committee members that since November 1942 three publications had appeared in the journal Nature dealing with the chemistry of penicillin. Much later, Kurt Wallersteiner, mentioned earlier in connection with vivicillin, was apparently proposing to publish a book on penicillin and had written to Florey about his intentions. Wallersteiner revealed in his letter that he was aware of there being different chemical forms of penicillin. This fact shocked Florey and he wrote to Mellanby with his concerns. Mellanby's reply dated 14th February, $1945^{76}$ was to deplore the «leakage of information» on penicillin. He reassured Florey that he would warn what he referred to as the «Security of Publications people» about the imminent publication of the book and would do his best to obtain a manuscript of the book for Florey to examine.

The suppression of information about what was a novel and highly effective therapy raised fundamental issues that touched on the very nature of democracy and its freedoms; Adams points to the conflict that existed

75. Sheehan, n. 39, p. 57-58.

76. Florey Archives. Royal Society, London. 98HF 36. 3. 117. 
in the United States between the Office of War Information (OWI) who believed its duty to be that of accurately and truthfully conveying wartime developments to the American public, and the COC who saw all publicity relating to penicillin as hindering its efforts to manage effectively the rationing of penicillin ${ }^{77}$. According to Adams the OWI wanted to distinguish itself from those agencies of totalitarian governments who sought to withhold the truth from their own people. In the words of its Director, Elmer Davies, «truth itself has become a more powerful weapon than ever before».

Adams has further argued that the notion of rationing of medical therapeutics was one that was fundamentally difficult for Americans to accept because of the social value placed upon personal health in the United States, and that the very idea of non-market rationing was one that would deeply have disturbed the American public ${ }^{78}$. The press avidly exploited anxiety over the rationing of penicillin to sell newspapers. The structure of the "Judge Keefer» story, first mentioned above ${ }^{79}$, is particularly revealing. The item began with the ultimately heart-warming story of how a little girl, Patsy Malone, was saved by penicillin. But the reader of the story would ultimately have been left with a bitter after taste, for it went on to relate how a teenager, Marie Barker, did not fare so well, and died for lack of penicillin. The girl's parents accepting that it was «necessary for [their] Government to refuse the penicillin» for the treatment of their daughter so that the life of a soldier, sailor or marine might be saved.

The general impression that media reports tried to convey of the typical recipient of penicillin was that of a serviceman gallantly and gloriously wounded in battle. Not included in this portrayal were the servicemen who had contracted sexually transmitted diseases (STDs) during service overseas. Penicillin offered rapid and effective cures of STDs never previously witnessed. For example, in 1940 the death rate from syphilis stood at 10.7 per 100, 000 cases, but with penicillin cure rates of 90 to $97 \%$ were routinely achieved ${ }^{80}$. Aside from considerations of morality, such conditions could just as well deplete the fighting strength of units. In Britain Winston Churchill personally sanctioned the use of penicillin for the treatment of

\footnotetext{
77. Adams, n. 28, p. 16

78. Adams, n. 28, p. 1.

79. The American Weekly, n. 29

80. Brandt, Allan M. No magic bullet: a social history of venereal disease in the United States since 1880. New York: Oxford University Press; 1985, p. 171.
} 
such cases ${ }^{81}$. Useful a contribution to the war effort as this was it would have been harder to justify to the deprived civilian population, and the use of penicillin in such applications never became public knowledge at any time during the war.

It is telling that the technique for producing homemade penicillin received such publicity in the United States - a country that possessed an efficient mechanism for distributing the antibiotic to civilian patients who met the criteria that had been established by Keefer's committee. Although only strictly limited amounts of the antibiotic were available, a dangerously ill American citizen suffering from an infection that was sensitive to penicillin stood a greater chance than the citizen of any other country on Earth of obtaining penicillin. However, under the onslaught of media reports proclaiming its unavailability such facts became immaterial. The concept of the manufacture of penicillin in the home grew out of a refusal to accept the reality of penicillin's shortage and unavailability.

In the absence of any officially approved method of supplying penicillin to meet civilian needs the authorities in Britain must have felt less secure with their policy of prioritising military needs for the antibiotic, and at one stage even considered - but then rejected-sanctioning vivicillin production as a means of satisfying civilian demands for penicillin ${ }^{82}$ : it seems that the deeply-held scepticism of prominent penicillin researchers ultimately won through. Those «amateurs» who were able to acquire penicillin-producing strains of $P$. notatum were restricted to cultivation by the so-called surface method which is intrinsically inferior to the submerged cultivation method and produces only low yields of penicillin. The complexity of the latter would have placed it entirely beyond the reach of anyone who was not specially trained and with access to the correct equipment. Moreover, acquisition of the correct constituents of culture media would have proved almost impossible, and those undertaking production would have had to substitute for these with heavily rationed foodstuffs such as sugar. As only strictly limited quantities of penicillin could be made by these methods the numbers of civilians who received treatment were probably numbered in the hundreds in both the United States and Britain.

81. Macfarlane, n. 7, p. 197

82. National Archives, London. Penicillin supplies: policy MH/58/360. 
Whilst the contribution to civilian health made by amateur producers of penicillin was fairly negligible, the same cannot so easily be said of the impact on civilian morale of their attempts as reported on in the media. As has been described, the mass circulation newspapers in Britain and the United States essentially kept the story alive however unrealistic attempts to produce the antibiotic independently of what might be termed «official endeavours» were $^{83}$. It may be argued that perhaps the true value of the concept of homemade penicillin was in creating in the minds of the public the idea that the gulf that appeared to exist in their being able to access the drug was not insurmountable and crucially, not directly related to the fortunes of the nation's forces on the battlefield.

\section{Acknowledgements}

I am grateful to Dr. Barry Holmes, Head of the NCTC, HPA, Colindale, London, for providing me with items correspondence dating from the Second World War. I am indebted to the staff of the Interlibrary Loans Service at Loughborough University for their unstinting efforts in obtaining materials for me for this article. I wish also to acknowledge the two anonymous reviewers of my first submission to this journal for their invaluable comments and suggestions.

83. The Times — uniquely amongst newspapers - attempted to prevent its readers from deluding themselves by pointing out the hopelessness of the «suggestion made in America and somewhat irresponsibly repeated here that crude penicillin grown (sic) on gauze would solve the problem of supply». The Times. 14 Dec 1943: 5. 